\title{
ДИСКУССИЯ МЕЖДУ МАРТИНОМ ХАЙДЕГГЕРОМ И ЭМИЛЕМ ШТАЙГЕРОМ
}

\begin{abstract}
Аннотация. Предметом рассмотрения в данной статье стала та часть переписки филолога Эмиля Штайгера и философа Мартина Хайдеггера, в которой ведётся обсуждение стихотворения Эдуарда Мёрике «К лампе». Внимание в статье обращено, как к самому стихотворению и его различным прочтениям у Хайдеггера и Штайгера, так и к тем методологическим позициям, которые и обуславливают главные различия в их интерпретациях. В применяемых Хайдеггером и Штайгером техниках толкования раскрывается в целом разница между философским и филологическим подходами к литературному тексту. Различия в подходах к стихотворению высвечиваются не только благодаря применению автором метода сравнительного анализа, но и благодаря герменевтическому проникновению в интенции каждого интерпретатора, каждый из которых, так или иначе, представляет целостный взгляд на исследовательскую проблему. Научная новизна исследования состоит в представлении дискуссии Хайдеггера и Штайгера в широком дискурсе диспута двух факультетов, в которых следуют различным стратегиям истолкования поэтических произведений. Автор, стремясь к объективности в рассмотрении исследовательских позиций каждой из сторон, приходит к выводу, что подход Хайдеггера ближе к раскрытию поэтической истины рассматриваемого стихотворения.

Ключевые слова: Хайдеггер, Штайгер, Мёрике, стихотворение "К лампе», Гёте, lucet, videtur, стиль, "искусство интерпретации», феноменология.
\end{abstract}

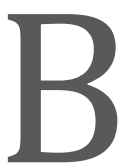
данной статье мы рассмотрим, как поразному можно подойти к интерпретации поэтического произведения, когда эта разность обусловлена не просто различием индивидуальностей авторов, но различием самих способов мышления, а именно, различием филологического и философского способов мышления.

Когда разности сталкиваются, то возникает поле напряжение. Формой интеллектуального напряжения стала дискуссия между философом Мартином Хайдеггером и филологом Эмилем Штайгером по поводу толкования лирического произведения Эдуарда Мёрике «К лампе». Эта дискуссия велась на протяжении нескольких лет и носила, в целом, приватный характер. С 1936 по 1969 гг. Штайгер и Хайдеггер обменивались письмами, в которых, в том числе, они говорили и о стихотворение Мёрике. Из переписки сохранились в основном письма Хайдеггера Штайгеру, так как Хайдеггер полученные письма не стремился сохранить.

По сравнению с текстом в «Истоке художественного творения» (пер. А.В. Михайлова), на который в данном исследовании мы будем в основном опираться, у Вернера Вогербауэра (Werner Wögerbauer) полное издание писем. Но и их недостаточно, чтобы «определить различия между философской и литературной герменевтикой» ${ }^{1}$, - пишет Вогербауэр. В данной статье мы помимо анализа ключевых текстов переписки, рассмотрим доклад Штайгера «Искусство интерпретации», а также седьмой параграф из книги Хайдеггера «Бытие и время», посвященный методу феноменологии.

$$
* * *
$$

Хайдеггер и Штайгер по-разному подошли к толкованию лирического произведения. Метод феноменологической герменевтики поэзии Хайдеггера существенно отличается от «искусства интерпретации» Штайгера, в котором он, несмотря на некоторые нововведения, в целом, продолжает следовать традиционным методикам толкования поэзии, принятым в филологии. В статье их подходы рассмотрены не только по отдельности. Проведен сравнительный анализ, благодаря которому

Wögerbauer, Werner. Der Briefwechsel zwischen Martin Heidegger und Emil Staiger // Geschichte der Germanistik. 2004. № 25/26. S. 36. 
выделены, как те области, в которой эти разные подходы столкнулись и пересеклись, так и области, в которых каждому подходу удалось сохранить свои индивидуальные особенности, обусловленные спецификой того или научного мышления.

Интерпретация стихотворения Мёрике «К Лампе» является одной из центральных тем писем Штайгера и Хайдеггера друг к другу. Основной спор разгорелся вокруг семантики слова "scheinen" из последней строки стихотворения. Хайдеггер полагает правильным переводить "scheinen" как "lucet" (светит). Штайгер же читает слово "scheinen" как "videtur" (кажется).

Штайгер дает психологическую характеристику состояния лирического героя стихотворения. Лирический герой, которым в данном стихотворении является сам автор стихотворения, согласно Штайгеру, не уверен в своих предположениях. Он не уверен, потому что «в этом доме, где висит лампа, он не чувствует себя хозяином...», но все же «он еще осмеливается, пусть наполовину, смотреть на себя как на посвященного»².

Стихотворение проникнуто настроением меланхолии, полагает Штайгер. Зала, в которой висит лампа, не является больше для него родным местом, но еще и не стала совсем чужим: она пробуждает воспоминания, она вызывает меланхолию. И именно «меланхолическая красота» создает особое очарование, которое присуще именно позднему поэту, оглядывающемуся назад в прошлое - в полную сил и уверенности в себе романтическую эпоху Гёте.

Штайгер рассматривает творчество Мёрике в историческом контексте, соизмеряя его творения с творениями Гёте. Сравнение с «солнцем» немецкой поэзии приходится не в пользу Мёрике. Для Штайгера Мёрике остается в тени Гёте, сияние его творчества - это пробиваемые сквозь темноту догорающие лучи заходящего солнца. Штайгер сравнивает последнюю строку из стихотворения «К лампе» Мёрике с почти тождественной по звучанию и значению строкой из второй части «Фауста» Гёте. И если у Гёте «прекрасное остается блаженным для себя самого», то у Мёрике, согласно Штайгеру: «прекрасное же - оно блаженным кажется в нем самом» ${ }^{3}$.

2 По поводу одного стихотворения Мёрике (Переписка Эмиля Штайгера с Мартином Хайдеггером) // Хайдеггер М. Исток художественного творения. М.: Академический проект, 2008. С. 397.

3 Там же. С. 398.
Штайгер не может поставить Мёрике на одну ступень с Гёте. Как поздний поэт, «Мёрике так далеко не заходит. Он не настолько полагается на самого себя, чтобы знать, каково на душе у красоты» ${ }^{4}$, - пишет он. Поэтому способ видения у них различен: «Он (Мёрике) смотрит на лампу не столько как на творение искусства, как смотрел бы не нее Гёте, почитая творение в сознании своего кровного родства с ним, не как на органическое создание, архитектонические законы которого близки законам строения человеческого тела и человеческого духа.... ${ }^{5}$.

Штайгер делает ударение на том, какой кажется красота. Красота кажется блаженной. Это не обманчивое свечение, но именно та красота, какая представляется поэту. Именно поэт дает оценку красоте лампы - и она представляется ему блаженной. Штайгер далек от феноменологического мышления Хайдеггера, то есть ему не представляется важной задачей открытие вещи такой, какой она есть по своей сути. Для Штайгера важен взгляд, каким меряет поэт лампу. Но этот взгляд со стороны, эта субъект-объектная позиция есть как раз то, что по существу не приемлет Хайдеггер. Расходятся они и в понимании цели использования древнего возвратного местоимения «в нем» (in ihm). Для Штайгера цель данного словоупотребления у Мёрике - усиление экспрессии отстраненности от лампы: «этим красота вновь отодвигается в свою даль...» ${ }^{6}$ Для Хайдеггера - усиление самодостаточности лампы.

Причины, по которым Штайгер читает слово «светить» как «кажимость», лежат в особенностях применяемой им методологии. О своей методологии работы с художественными произведениями Штайгер рассказывает в работе «Искусство интерпретации» (1950). За теоретической частью работы следует практическая часть - апробация новой методологии на примере толкования стихотворения Мёрике «К лампе» (1846).

Штайгер в своем толковании пользуется такой заимствованной у Хайдеггера философской техникой как герменевтический круг - постижение целого из единичного и единичного из целого. Но применение в науках о литературе техник, выработанных в смежных областях знания, не мо-

\footnotetext{
4 Там же. С. 398.

5 Там же. С. 398.

6 Там же. С. 398.
} 


\section{Философия и культура 10(82) • 2014}

жет быть произведено без некоторых изменений, касающихся той отличительной области, которая собственно характеризует литературу как отдельную науку. Эта отличительная область есть эстетика, которая для Штайгера лежит в сфере чувств и переживаний. В соответствии с данной эстетической функцией литературы методология работы с поэтическими произведениями должна учитывать сферу субъективной чувственности.

Чувство - это наиболее верный способ войти в герменевтический круг. Но чувство должно не только предварять, но и сопровождать литературные исследования на всем пути следования от гипотетических предположений до удостоверенных утверждений. Штайгер придает большое значение субъективному чувству и субъективному видению в своих методологических разработках. Он сближает эстетические и эпистемологические аспекты исследования. Без чувственного проникновения в текст, без эмпатии, становится невозможным полное раскрытие истины стихотворения.

Но Штайгер мыслит чувство не просто как эмпирическую данность - как определенного рода эмоциональное возбуждение, но как сложный психический комплекс, в основании которого лежит неуловимый духовный настрой. Духовный настрой как базис лежит в основании любого чувственного волнения. «Духовный базис необходим не только для первого столкновения, но также для постоянной самопроверки» ${ }^{7},-$ пишет Штайгер.

При первом знакомстве со стихотворением, полагает Штайгер, мы не можем сразу проникнуть ни в целое содержания, ни в его частности, но мы сразу улавливаем его ритм, на котором покоится «стиль поэтической структуры» ${ }^{8}$. «Я называю это чувство ритмом, - пишет далее он, - в том особенном смысле, который ему придавал Густав Бекинг (Gustav Becking) в своей книге "Der musikalische Rhythmus als Erkenntnisquelle" ${ }^{9}$.

Этот ритм, который в нас возникает уже при первом чтении стихотворения, может уловить тот предельный индивидуальный стиль, который присущ именно этому поэту. Штайгер понимает стиль в широком смысле как то, что согласует собой все в

\footnotetext{
7 Staiger, Emil; Spitzer, Leo; Lang, Berel; Ebel, Christine. A 1951 Dialogue on Interpretation: Emil Staiger, Martin Heidegger, Leo Spitzer // PMLA. May, 1990. Vol. 105. № 3, Special Topic: The Politics of Critical Language. S. 412.

8 Ebd. S. 412.

9 Ebd. S. 411.
}

стихотворение, от композиции до его идеи: «в стиле, как в едином, согласуется все многообразие» ${ }^{10}$. «Безошибочный индивидуальный стиль поэтического произведения» ${ }^{11}$ и есть цель интерпретации Штайгера. И этот стиль не может быть сразу схвачен в рамках какой-либо концепции, полагает Штайгер. Стихотворение Мёрике принято относить к направлению бидермейер (Biedermeier), но в рамках данного направления бесчисленное множество произведений. Поэтому, полагает он, необходимо распознать отличительную красоту стихотворения Мёрике. Стиль у Мёрике Штайгер определяет как «изящный» (graceful) в подлинном значении этого слова.

Герменевтический путь, который он проходит, чтобы убедиться в своем первом впечатлении от стихотворения, а именно, как стихотворении позднего поэта, проникнутое настроением меланхолии об ушедшей эпохе романтизма и ее классиков, он описывает следующим образом: «В начале мы попытались войти в пространство произведения искусства извне путем краткой рефлексии лингвистической традиции и жизни поэта. Сейчас мы должны выйти из пространства поэзии с тем, чтобы полнее ощутить атмосферу стихотворения» ${ }^{12}$.

Штайгер суммирует слагаемые, полученные на этапах прохождения герменевтического круга. Мы выделим лишь некоторые важные из них. Первое слагаемое - время написания стихотворения. Оно было написано, как определяет Штайгер, «в 1846 году после "Idylle vom Bodensee" и вместе c "Götterwink", "Das Bildnis der Geliebten", "Datura suaveolens", "Weihgeschenk", "In Schrift auf eine Uhr" »" то есть в поздний период творчества поэта. Второе слагаемое - форма стихотворения. Штайгер относит стихотворение Мёрике к классической традиции стихосложения. Размер, которым написано стихотворение - «ямбический триметр без двухсложных безударных слогов и без кумулятивного эффекта сильных ударений, таких как в “Пандере” и во второй части “Фауста" Гёте» ${ }^{14}$. Также он указывает, что «регулярный стих Мёрике с его устойчивой последовательностью ударных и безударных слогов» ${ }^{15}-$

\footnotetext{
10 Ebd. S. 412.

1 Ebd. S. 414

2 Ebd. S. 417.

13 Ebd. S. 413

14 Ebd. S. 413

15 Ebd. S. 413
} 
это классический шестистопный стих, или иначе он называется сенар (senarius). Но, несмотря на то, что форма стихотворения наследует классические образцы, атмосфера стихотворения, которая есть третье слагаемое, уже иная. Мёрике стоит на границе эпох, в конце эпохи романтизма. Он продолжает придерживаться классических образцов, но они уже не звучат так жизненно и ярко как раньше, ибо эпоха, в которой эти образцы создавались, постепенно уходит, уступая место новой эпохе. Искусство у Мёрике перестает быть образцом жизни. «Социальные и космополитические цели немецкого классического периода больше не существуют» ${ }^{16}$.

Итак, каждое из слагаемых соответствует предварительному чувству Штайгера, в ритме которого обнаруживается сам поэтический стиль. Стихотворение Мёрике - меланхолия по ушедшей эпохе романтизма. Стиль, безусловно, не есть простая сумма слагаемых, но есть то постоянное значение, на которое умножается каждое слагаемое, сумма которых и образует целое стихотворения. И о сумме здесь говорится не в строгом математическом значении, а в том ее несущем смысле действии собирания, которое оно производит как определенная операция, необходимая в мире. И здесь мы могли бы сказать словами Хайдеггера, в стихотворении мир собирается и раскрывается. Но Штайгер все же действие собирания понимает иначе. Главным конституирующим фактором стихотворения он полагает стиль, а не истину бытия. Эстетике стихотворения Штайгер придает большее значение, чем онтологии. «Работа достигает совершенства, когда все гармонизировано в его стиле» ${ }^{17}$, - пишет он.

Но, несмотря на главенство стиля в его методологических установках, Штайгер не может отрицать значимость категории истины в системе «автор-произведение-интерпретаторы», потому как не могут существенно разниться между собой мнения, с одной стороны, автора и толкователей, а с другой стороны, самих толкователей. Единство понимания стихотворения есть условие его истинности.

Исследователь Маркус Вайлд (Markus Wild) полагает, что концепция истины, которой придерживается Штайгер, соответствует не корреспондентской, но когерентной теории, понимая под когерентностью согласованность различных про-

16 Ebd. S. 417.

17 Ebd. S. 414. чтений стихотворения, в основании которых субъективное чувство интерпретатора ${ }^{18}$. Если один интерпретатор убеждается в истинности своего индивидуального прочтения стихотворения путем нахождения соответствующих сведений, и если другой интерпретатор тоже путем соответствующих фактов может подтвердить свое интуитивное переживание поэзии, то тогда, как рассуждает Штайгер, если их выводы в существенном совпадают, несмотря на возможные незначительные расхождения, толкование истинно.

Обратимся теперь к Хайдеггеру и посмотрим, как он читает стихотворение. Осенью 1950 г. Хайдеггер оказался в числе слушателей доклада Штайгера «Искусство интерпретации», в который, как было уже сказано, он включил и текст интерпретации стихотворения Мёрике. Свое несогласие с некоторыми утверждениями Штайгера относительно стихотворения Хайдеггер выразил в адресованном ему письме от 13 декабря 1950 г., который Штайгер не оставил без внимания. В последовавших затем письмах друг другу они продолжили обсуждение стихотворения Мёрике «К лампе».

Если Штайгер прочитывает слово "scheinen" как "videtur" (кажется), то Хайдеггер как "lucet" (светится). И читает он последнее стихотворение Мёрике следующим образом: но то, что прекрасно - оно сияет, как истинное произведение искусства, блаженно в самом себе. Свечение - внутренняя сущность лампы. «"Блаженно” - это лишь сущностное следствие “свечения в себе самом"» 19 .

Хайдеггер согласен со Штайгером в том, что стихотворение Мёрике относится к началу позднего искусства. Но в отличие от Штайгера он сильнее раздвигает историческое пространство, поднимаясь до философского духа эпохи, в котором сильнее всего ощущалось веяние философии Гегеля. Хайдеггер ссылается на лекции по эстетике Гегеля, в которых он, в частности, пишет, что «прекрасное тем самым определяет себя как чувственное свечение идеи» ${ }^{20}$. Прекрасная лампа, светящаяся в стихотворении, - это «символ художественного

\footnotetext{
18 Wild, Markus. Heidegger, Staiger, Muschg. Warum lesen wir? // Heidegger und die Literatur / Herausgegeben von Günter Figal und Ulrich Raulff. 2012. S. 112.

19 По поводу одного стихотворения Мёрике (Переписка Эмиля Штайгера с Мартином Хайдеггером) // Хайдеггер М. Исток художественного творения. М.: Академический проект, 2008. С. 399.

20 Там же. С. 400.
} 


\section{Философия и культура 10(82) • 2014}

творения» ${ }^{21}$. Хайдеггер полагает, что в стихотворении речь идет о сущности произведения искусства. Штайгеру же представляется, что хайдеггеровская склонность к философскому обобщению может нести опасность для индивидуальной сущности поэтического творчества.

Возможно, что Хайдеггер, относя Мёрике к философствующим поэтам, невольно сравнивает его с Гёльдерлином, поэзии которого он посвятил немало своих трудов. Хайдеггер верит, что чем философичней поэт, тем делается он «более поэтически творящим»22. Неоспоримым свидетельством занятий Мёрике философией Хайдеггер считает тот факт, что Фридрих Теодор Фишер, автор труда «Эстетика, или Наука о прекрасном», был «постоянным советчиком его в вопросах эстетики» ${ }^{23}$.

Но по сведениям Штайгера, Мёрике не имел интереса к философии, и его изучение философии было весьма поверхностным. Мёрике был не склонен «к серьезной работе мысли» ${ }^{24}$, - пишет он. Штайгер считает возможным критиковать подход Хайдеггера к анализу стихотворения за его «схоластичность». Он полагает, что столь лирическое стихотворение не может быть пропущено через строгие понятия, описывая язык Мёрике как «неопределенный, скользящий, неуловимый, предусмотрительно-осторожный, иной раз хитро переливчатый» 25 . Но доказывая правомерность философского подхода к анализу стихотворения, Хайдеггер пишет, что «в те времена благодаря господству философии Гегеля и его учеников значение "scheinen" в смысле "светящегося самовыявления налично присутствующего" висело в воздухе» ${ }^{26}$. Стихотворение Мёрике неотделимо от общефилософского дискурса того времени: оно окружено атмосферой гегелевской идеалистической философии.

И если Хайдеггер ставит ударение на смысловом глаголе “ist” (есть, является), показывая бытийственную сторону лампы, то Штайгер акцентирует внимание на том, какой кажется лампа поэту. В противоположность психологической характеристике, которую Штайгер дает лирическому герою, Хайдеггер фундирует свой анализ на фено-

\footnotetext{
21 Там же. С. 399.

22 Там же. С. 405

23 Там же. С. 401.

24 Там же. С. 402.

25 Там же. С. 403.

6 Там же. С. 405.
}

менологии. Феноменология как фундаментальная онтология «имеет темой онтологически-онтическое особенное сущее, присутствие», и, основываясь на данной теме, решает «вопрос о смысле бытия вообще» ${ }^{27}$. Попав в поле феноменологического разыскания и феноменологической обработки, вещи на выходе становятся феноменами, дело с которыми в дальнейшем ведет онтология.

Феномен ( $\varphi \alpha \iota v o ́ \mu \varepsilon v o v)$ в переводе с древнегреческого означает то, «что показывает себя, самокажущее, очевидное» ${ }^{28}$. Феномены ( как в целом сущее ( $\tau \grave{\alpha}$ ởv $\alpha$ ) «суть тогда совокупность того, что лежит на свету или может быть выведено на свет» ${ }^{29}$. Феномен как «само-по-себесебя-кажущее» следует отличать от феномена как «выглядящее так словно», ибо бытие сущего складывается из двух дополняющих друг друга модусов - потаенности и казания ${ }^{30}$. То, что себя кажет, редко есть полная и абсолютное казание себя, ибо казание фундировано на скрытом. Вот это скрытое, что еще лежит под определенным казанием себя вещи, и есть подлинный предмет феноменологии.

Штайгер в своем анализе стихотворение Мёрике принимает лишь одну сторону феномена - кажимость, отвергая другую - потаённость. Но только их единство образует целое феномена. Хайдеггер в своем письме Штайгеру пишет: «по сути же дела, слово scheinen в смысле “только казаться, будто...” никогда по-настоящему не мыслится, если не мыслится лежащая в его основе область свечения в смысле выявляющего саморазверзания чего-либо налично присутствующего. Грече-

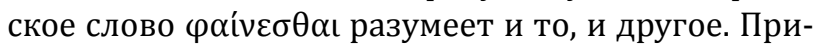

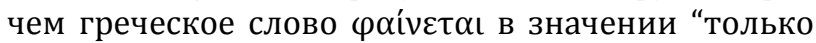
кажется, что...” все равно продолжает говорить иное, нежели римское videtur, которое исходит от наблюдающего» ${ }^{31}$.

Поэтому видимость, «только казаться, будто...», не есть лишение себя истинной сущности, но лишь ее утаивание, то есть пустая кажимость, а не казание по сути.

\footnotetext{
27 Хайдеггер М. Бытие и время. СПб.: Наука, 2006. С. 37.

28 Там же. С. 28.

29 Там же. С. 28.

30 Там же. С. 28.

31 По поводу одного стихотворения Мёрике (Переписка Эмиля Штайгера с Мартином Хайдеггером) // Хайдеггер М. Исток художественного творения. М.: Академический про-
} ект, 2008. С. 405. 
Сущность лампы как закон внутреннего действия и внешнего самопроявления - это свечение, и свечение разное. С одной стороны, ее свет является видимым, чувственно воспринимаемым. Освящая, лампа собирает все присутствующее в единое целое, создаваемое пространством света. И здесь возможны различные коннотативные значения, на которые и обращает внимание Штайгер, определяя язык Мёрике, как многообразно переливчатый. Хайдеггер же, следуя гегелевской эстетике, созерцает идею прекрасной лампы, которая находит отражение в ее чувственном свечении. Как мы уже упомянули, согласно Гегелю, «прекрасное тем самым определяет себя как чувственное свечение (Scheinen) идеи»32. Онтическое свечение как чувственное свечение и онтологическое свечение как самовыявление идеи - это две стороны бытия лампы как феномена.

Хайдеггер, уточняя семантику оборота «в нем самом» ("In ihm selbst"), про который Штайгер упомянул как про оборот, переданный на швабском диалекте, пишет, что «в нем самом» относится к глаголу «светит» ("scheint"), а не к наречию «блаженно» ("selig"). Лампа светится изнутри. Свечение есть, прежде всего, внутренняя сущность лампы. В слове «в нем» выражается нечто, что «не обладает самосознанием самого себя», поэтому свечение лампы есть «некоторое сияние, или свечение без самосознания» ${ }^{33}$.

Блаженное свечение прекрасной лампы есть подлинное, а не кажущееся сияние. Блаженное сияние лампы - метафора сияния истины стихотворения как подлинного произведения искусства. Сиянием лампы, чувственным свечением истины, освещается все стихотворение. И если лампа символ стихотворения, то само стихотворение - это «покоящийся в языке символ художественного творения» ${ }^{34}$.

Светом лампы освещается все стихотворение, и этот свет становится искаженным, если само свечение, как предлагает Штайгер, воспринимать как кажущееся (videtur). И тогда неизбежно искажается та сущность истины искусства, которая, по видению Хайдеггера, выражается в стихотворении, ибо кажущееся сияние можно рассмотреть только как сияние, отображающееся в субъективной зрительной перспективе.

\footnotetext{
32 Там же. С. 400.

33 Там же. С. 400.

34 Там же. С. 399.
}

Истина - это исток подлинного произведения искусства. В свете этой истины, свечения лампы, сияет все сущее, которое вошло посредством языка в пространство творения искусства. В открытом пространстве искусства в свете истины все сущее приходит в несокрытость, к своей истине, как наиболее подлинной возможности бытия.

Свечение мыслится Хайдеггером в качестве актуального бытия, в качестве события истины (Wahrheitsereignis), которое происходит каждый раз, когда открывается пространство искусства стихотворения. Это каждый раз новое «здесь и сейчас» мы можем назвать перетекающимся моментом вечности. В этом перетекающемся из одного «здесь и сейчас» в другое «здесь и сейчас» моменте вечности разворачивается действие бытия - свечение. Свечение лампы отсылает к незримому свечению истины бытия. Мы можем сказать, что благодаря открытию истины стихотворения, в котором учреждается сущность искусства, мы трансцендируем к самой истине бытия.

Штайгер признает мистичность языка Хайдеггера, его устремленность к сияющей истине самой по себе. И по мысли Хайдеггера, Мёрике смог общими штрихами запечатлеть ее, по крайней мере, ее явленную в мир сущность. Философская отвлеченность М. Хайдеггера противостоит стремлению Э. Штайгера к филологической точности. Хайдеггер стремится преодолеть чистые факты и раскрыть в них эйдетические сущности. Сами по себе факты ничего не говорят, но они могут отсылать к тем неизменных сущностям, благодаря которым сами факты обретают собственную фактичность, то есть бытие в единственном и уникальном образе. Но образ всегда отсылает к вещи самой по себе, к потаенной истине ее сущности, которая проглядывает в образе. Истина Хайдеггера - непотаенность - находится в тесной и неразрывной связи с бытием. Так, поясняя Штайгеру в одном письме значение слова $\alpha \hat{\lambda} \theta \dot{\theta} \iota \alpha$, Хайдеггер пишет о близости этого слова к словам

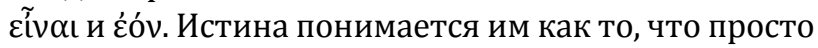
есть, и она «ни пучина, ни тайный смысл, ни нечто хаотическое» ${ }^{35}$. Штайгер же отрицает, что лампа в стихотворении несет символическую полноту невыразимой полноты бытия.

Говоря языком постструктуралистической философии, мы можем сказать, что стихотворение

35 Wögerbauer, Werner. Der Briefwechsel zwischen Martin Heidegger und Emil Staiger // Geschichte der Germanistik. 2004. № 25/26. S. 51. 


\section{Философия и культура 10(82) • 2014}

как произведение искусства - это метатекст, то есть текст как знак, обладающий определенным значением. Но в стихотворении как знаке первого уровня могут содержаться знаки второго и третьего уровней. Создаваемый в стихотворении Мёрике образ лампы, символ стихотворения, - это знак второго уровня, внутри которого разворачивается текст третьего уровня. Такой способ мышления позволяет созерцать стихию мысли поэта в многомерном измерении.

Для Штайгера образцом поэтического искусства является Гёте, тогда как для Хайдеггера - поэт Гёльдерлин. Штайгер полагает, что направленность Гёльдерлина на «невозможное» отвечает духовным исканиям Хайдеггера ${ }^{36}$. Штайгер стремится обосновать различия в интерпретациях также различием языков, на которых они говорят. Мысля на философском языке, Хайдеггер стремится и язык Мёрике мыслить как философский, тогда как Штайгер как сугубо лирический. «Но ведь язык Гёльдерлина, безусловно, более философичен, чем язык Мёрике» ${ }^{37},-$ пишет Штайгер.

В письме от 6 января 1951 г. Штайгер, уступая критике Хайдеггера, поясняет, что он никогда не мыслил слово "scheinen" в значении фантома, то есть того, что «только выглядит, но не есть...» ${ }^{38}$. Выбирая значение "videtur", он признает множество других значений, полагая, что каждое из них вполне уместно в таком скользящем языке как язык Мёрике. "Videtur" является превалирующим значением, полагает Штайгер, в силу эпигонской ситуации, потому как «поэт поздний, вправе лишь предполагать» ${ }^{39}$.

Для Штайгера Мёрике - поэт, чье творчество оказалось в тени одного из великих поэтов Германии Гёте. Солнце немецкой поэзии не может быть зажжено снова. Культура Германии еще греется в закатных лучах поэзии великого немца. Поэтому и грусть, наполнившая стихотворение, как душевное состояние поэта - это грусть об ушедшей классической эпохе немецкой культуры. Мёрике творит свое стихотворение, уже не стремясь создать чтолибо монументальное.

\section{$36 \quad$ Ebd. S. 49.}

37 По поводу одного стихотворения Мёрике (Переписка Эмиля Штайгера с Мартином Хайдеггером) // Хайдеггер М. Исток художественного творения. М.: Академический проект, 2008. С. 404.

38 Там же. С. 413.

39 Там же. С. 403.
Феноменологически раскрывая структуру слова "scheinen", Хайдеггер показывает, что даже если мы это слово мыслим со значением «казаться», то мы никогда не сможем мыслить только одно это значение. Это значение отражает лишь внешнее вещи, которое невозможно без иной, ее подлинной сущности, которая стоит за этим явлением. Следовательно, самому этому слову имманентно принадлежит та основа, на которой проявляется ее казание блаженным.

Подлинное и только видимое раскрытие сущности - эти два значения в греческом слове $\varphi \alpha i ́ v \varepsilon \sigma \theta \alpha \mathrm{l}$, по мысли Хайдеггера, максимально приближены друг другу, ибо сами значения исходят из самой сущности вещи, «нежели римское videtur, которое исходит от наблюдающего» ${ }^{40}$. Хайдеггер, таким образом, разделяет два вида кажимости. Первый вид, предлагаемый им, это кажимость, выявляющаяся в самом художественном творении. Второй вид - это кажимость как такое видение субъекта, которое им с точностью внутренне не удостоверено. Эта второго рода кажимость, которая мыслится в слове videtur, Хайдеггер считает не применимым к интерпретации слова scheinen, которым выявляется сущность художественного творения, ибо тогда само творение слова и то, что послужило образом для этого творения, превращаются в пустую оболочку.

«Стихотворение возжигает прекрасную лампу» ${ }^{41}$ : стихотворение творит лампу в ее истине. И в стихотворении она же именуется «художественным созданием» ${ }^{42}$. Сказанное творением о творении составляет заключительную часть стихотворения. Эта часть отделяется от всех остальных частей знаком тире - подчеркивается ее обособленность. В ней ставится проблема: «кто же еще внимает художественному созданию в его подлинности, в его настоящей сущности?» ${ }^{43}$ Поставленный риторически вопрос неявно содержит в себе и ответ - лишь немногие. В этом причина печали, и настроением печали проникнуто все стихотворение. Для Хайдеггера настроение печали не связано с эпигонской ситуацией.

Грусть в стихотворении подчеркивает одиночество поэта, открывшего в своем созерцании пре-

\footnotetext{
40 Там же. С. 406.

41 Там же. С. 409.

42 Там же. С. 409.

43 Там же. С. 410.
} 
красный облик подлинного творения искусства. Красота творения, как лик пребывающий внутри творения истины, бытийствует в состоянии свободы. «Красота остается тем, что она есть», и она «бла- женно светит в нем самом» ${ }^{44}$ - в подлинном художественном творении, которым является прекрасная лампа. Слово «есть» подчеркивает подлинность бытия прекрасного, подлинность его свечения.

\section{Список литературы:}

1. Иванова Е.Р. Предметный мир в поэзии Эдуарда Мёрике // Вестник удмуртского университета. 2013. Вып. 4. С. 88-92.

2. По поводу одного стихотворения Мёрике (Переписка Эмиля Штайгера с Мартином Хайдеггером) // Хайдеггер М. Исток художественного творения. М.: Академический проект, 2008. 528 с.

3. Хайдеггер М. Бытие и время. СПб.: Наука, 2006. 450 с.

4. Appelbaum Graham, Ilse. Zu Mörikes Gedicht «Auf Eine Lampe» // Modern Language Notes. May, 1953. Vol. 68. № 5. P. 328334.

5. Holschuh, Albrecht; Lang, Berel; Lindenberger, Herbert. Interpreting a Pronoun in Mörike // PMLA. Mar., 1991. Vol. 106. № 2. P. 312-314.

6. Staiger, Emil; Spitzer, Leo; Lang, Berel; Ebel, Christine. A 1951 Dialogue on Interpretation: Emil Staiger, Martin Heidegger, Leo Spitzer // PMLA. May, 1990. Vol. 105. № 3, Special Topic: The Politics of Critical Language. P. 409-435.

7. Wallace, Martin. The Hermeneutic Circle and the Art of Interpretation // Comparative Literature. Spring, 1972. Vol. 24 . № 2. P. 97-117.

8. Wild, Markus. “Schon unser Briefwechsel hat das Gedicht allzu schwer belastet”. Staiger und Heidegger über Mörikes „Auf eine Lampe" // Kontroversen in der Literaturtheorie/ Literaturtheorie in der Kontroverse. Publikationen zur Zeitschrift für Germanistik. Band 19. Peter Lang, 2007.514 p.

9. Wild, Markus. Heidegger, Staiger, Muschg. Warum lesen wir? // Heidegger und die Literatur. Herausgegeben von Günter Figal und Ulrich Raulff. 2012. $160 \mathrm{~s}$.

10. Wögerbauer, Werner. Der Briefwechsel zwischen Martin Heidegger und Emil Staiger // Geschichte der Germanistik. 2004. № 25/26. S. 34-79.

\section{References (transliteration):}

1. Ivanova E.R. Predmetnyi mir v poezii Eduarda Merike // Vestnik udmurtskogo universiteta. 2013. Vyp. 4. S. 88-92.

2. Po povodu odnogo stikhotvoreniya Merike (Perepiska Emilya Shtaigera s Martinom Khaideggerom) // Khaidegger M. Istok khudozhestvennogo tvoreniya. M.: Akademicheskii proekt, 2008. $528 \mathrm{c}$.

3. Khaidegger M. Bytie i vremya. SPb.: Nauka, 2006. $450 \mathrm{~s}$.

4. Appelbaum Graham, Ilse. Zu Mörikes Gedicht «Auf Eine Lampe» // Modern Language Notes. May, 1953. Vol. 68. № 5. P. 328334.

5. Holschuh, Albrecht; Lang, Berel; Lindenberger, Herbert. Interpreting a Pronoun in Mörike // PMLA. Mar., 1991. Vol. 106. № 2. P. 312-314.

6. Staiger, Emil; Spitzer, Leo; Lang, Berel; Ebel, Christine. A 1951 Dialogue on Interpretation: Emil Staiger, Martin Heidegger, Leo Spitzer // PMLA. May, 1990. Vol. 105. № 3, Special Topic: The Politics of Critical Language. P. 409-435.

7. Wallace, Martin. The Hermeneutic Circle and the Art of Interpretation // Comparative Literature. Spring, 1972. Vol. 24. № 2. P. 97-117.

8. Wild, Markus. “Schon unser Briefwechsel hat das Gedicht allzu schwer belastet”. Staiger und Heidegger über Mörikes „Auf eine Lampe" // Kontroversen in der Literaturtheorie/ Literaturtheorie in der Kontroverse. Publikationen zur Zeitschrift für Germanistik. Band 19. Peter Lang, 2007. 514 p.

9. Wild, Markus. Heidegger, Staiger, Muschg. Warum lesen wir? // Heidegger und die Literatur. Herausgegeben von Günter Figal und Ulrich Raulff. 2012. $160 \mathrm{s.}$

10. Wögerbauer, Werner. Der Briefwechsel zwischen Martin Heidegger und Emil Staiger // Geschichte der Germanistik. 2004. № 25/26. S. 34-79. 